\title{
Involvement of Brain 5-HT 7 Receptors in the Formation of Stress Adaptation in Mice
}

\author{
Kotaro Takeda, Minoru Tsuji*, Kazuya Miyagawa and Hiroshi Takeda \\ Department of Pharmacology, School of Pharmacy, International University of Health and Welfare, 2600-1 Kitakanemaru, Ohtawara, \\ Tochigi 324-8501, Japan
}

\begin{abstract}
Background/Objectives: Impairment of the ability to adapt to stress in animals may contribute to some stressrelated psychiatric disorders, such as anxiety and depression. A growing body of evidence has suggested that the brain's serotonin (5-HT) nervous system may play an important role in the etiology, expression and treatment of anxiety and depression. The aim of the present study was to examine whether brain $5-\mathrm{HT}_{7}$ receptors are involved in the formation of stress adaptation.
\end{abstract}

Methods: Male ICR mice were either exposed to repeated restraint stress for 60 or $240 \mathrm{~min} /$ day (stressed group) or left in their home cage (non-stressed group) for 1 or 14 days. The emotionality of mice was estimated by the hole-board test. The levels of $5-\mathrm{HT}_{7}$ receptor expression and extracellular signal-regulated kinase $1 / 2$ (ERK) phosphorylation were assessed by western blot analysis.

Results: A single exposure to restraint stress for $60 \mathrm{~min}$ induced a decrease in head-dipping behavior in the hole-board test. This emotional stress response was not observed in mice that had been exposed to repeated restraint stress for $60 \mathrm{~min} /$ day for 14 days, which confirmed the development of stress adaptation. In contrast, mice that were exposed to restraint stress for $240 \mathrm{~min} /$ day for 14 days did not develop this stress adaptation, and still showed a decrease in head-dipping behavior. Increases in $5-\mathrm{HT}_{7}$ receptor protein and ERK phosphorylation were observed in the frontal cortex and hippocampus of stress-adaptive, but not stress-maladaptive, mice. The decreased emotionality observed in stress-maladaptive mice was significantly recovered by chronic treatment with $\mathrm{LP}-12$, a selective $5-\mathrm{HT}_{7}$ receptor agonist, immediately after daily exposure to stress.

Conclusion: The present findings suggest that the brain $5-\mathrm{HT}_{7}$ receptor-ERK system may play an important role in the formation of stress adaptation. Furthermore, stimulation of $5-\mathrm{HT}_{7}$ receptors may have a beneficial effect on stress adaptation and alleviate the emotional abnormality observed under conditions of excessive stress.

Keywords: Stress adaptation; 5- $\mathrm{HT}_{7}$ receptor; ERK phosphorylation; Hole-board test; Mouse.

Abbreviations: 5-HT, serotonin; ERK, extracellular signal-regulated kinase 1/2; LP 12, 4-(2-Diphenyl)- $N$-(1,2,3,4-tetrahydronaphthalen-1-yl)-1-piperazinehexanamide; mRNA, messenger RNA; i.c.v., intracerebroventricularly; GAPDH, glyceraldehyde 3-phosphate dehydrogenase; MAP, mitogen-activated protein; TrkB, tropomyosinrelated kinase B; BDNF, brain-derived neurotrophic factor; $\mathrm{mTOR}$, mammalian target of rapamycin; Cdc42, cell division cycle 42; Cdk5, cyclin-dependent kinase 5; CREB, cAMP response element-binding protein.

Received: December 07, 2016; Revised: January 26, 2017; Accepted: February 03, 2017

*Correspondence to: Minoru Tsuji, Department of Pharmacology, School of Pharmacy, International University of Health and Welfare, 2600-1 Kitakanemaru, Ohtawara, Tochigi 324-8501, Japan. Tel: +81-287-24-3489, Fax: +81-287-24-3521, E-mail: mtsuji@iuhw.ac.jp

How to cite this article: Takeda K, Tsuji M, Miyagawa K, Takeda H. Involvement of Brain 5- $\mathrm{HT}_{7}$ Receptors in the Formation of Stress Adaptation in Mice. J Explor Res Pharmacol 2017;2(1):21-30. doi: 10.14218/JERP.2016.00035.

\section{Introduction}

The ability to adapt to stress is an important defensive function of living things and impairment of this ability in animals may contribute to some stress-related disorders. Thus, identification of the brain mechanisms that contribute to stress adaptation could help to pave the way for new therapeutic strategies for stress-related mood disorders, such as anxiety and depression. Evidence obtained in our previous studies suggests that the brain's serotonin (5-HT) nervous systems, especially that involving $5-\mathrm{HT}_{1 \mathrm{~A}}$ receptors, may be involved, at least in part, in the development of adaptation to stress. ${ }^{1-4}$

There are now believed to be seven 5-HT receptor familiescollectively known as 5- $\mathrm{HT}_{1-7}$ - that comprise a total of 14 structurally and pharmacologically distinct 5 -HT receptor subtypes. ${ }^{5}$ The $5-\mathrm{HT}_{7}$ receptor is the most recently identified member of the 
family of G protein-coupled 5-HT receptor subtypes. ${ }^{6,7}$ Studies using autoradiography, in situ hybridization, radioligand binding and immunohistochemistry techniques have shown that $5-\mathrm{HT}_{7}$ messenger (m)RNA and receptor protein have a similar abundant distribution in various brain regions (i.e. the cerebral cortex, hippocampus, thalamus, amygdala and hypothalamus). ${ }^{6,8,9}$ The expression and distribution of mRNA and proteins for $5-\mathrm{HT}_{7}$ receptors in the limbic structures suggest that they may play a role in the regulation of emotional as well as cognitive functions. Indeed, previous behavioral pharmacological studies have suggested that $5-\mathrm{HT}_{7}$ receptor antagonists exert anxiolytic and antidepressive effects. ${ }^{10-13}$ Interestingly, it has also been recently reported that $5-\mathrm{HT}_{7}$ receptors are highly co-expressed with 5- $\mathrm{HT}_{1 \mathrm{~A}}$ in brain regions implicated in the regulation of emotionality, and these receptors have been shown to form heterodimers both in vitro and in vivo. ${ }^{14}$ Considering our previous findings and these more recent reports led us to speculate that brain $5-\mathrm{HT}_{7}$ receptor may play a significant role in the development of stress adaptation.

A series of behavioral experiments have demonstrated that repeated exposure to the same type of stress stimuli diminishes acute stress responses. For example, Kennett et al. ${ }^{15-17}$ reported that rats exposed to a single restraint stress exhibited a reduction in locomotion in an open field and that this behavioral change disappeared after repeated exposure to restraint stress. Other researchers have described similar behavioral adaptive responses to stress stimuli, ${ }^{18-20}$ suggesting that this animal model may be useful for investigating the mechanisms of stress adaptation. In addition, to further characterize models of stress adaptation, we recently examined behavioral responses in mice that were produced by either single or repeated exposure to restraint stress for 60 or $240 \mathrm{~min}^{21}$

A single exposure to restraint stress reduces head-dipping behavior of mice in the hole-board test, which is a good index for evaluating emotionality and this stress response is not seen in mice that are exposed to repeated restraint stress for $60 \mathrm{~min} /$ day for 14 days, which confirms the development of stress adaptation. ${ }^{22-26}$ However, mice that were exposed to restraint stress for $240 \mathrm{~min} /$ day for 14 days did not show this adaptive response to stress stimuli, but did show a decrease and increase in the weights of the thymus and adrenal gland respectively. Such maladaptation to stress stimuli and morphological abnormalities in organs suggest that the mice were unable to adapt to stressful conditions. Thus, we can create stress-adaptive and -maladaptive models in mice by repeatedly exposing rats to different degrees of restraint stress. ${ }^{21}$

In the present study, we carried out behavioral and biochemical experiments to obtain evidence that the brain's $5-\mathrm{HT}_{7}$ receptor plays a role in the formation of stress adaptation using stress-adaptive and -maladaptive modeled mice.

\section{Materials and methods}

\section{Animals}

Male ICR mice (Japan SLC, Inc., Shizuoka, Japan), weighing 25-30 g, were housed at a room temperature of $23 \pm 1{ }^{\circ} \mathrm{C}$ with a 12-h light-dark cycle (light on 7:00 a.m. to 7:00 p.m.). Food and water were available ad libitum. All experiments were carried out in the light phase of the cycle. The present studies were conducted in accordance with the Guide for the Care and Use of Laboratory Animals as adopted by the Committee on the Care and Use of Laboratory Animals of the International University of Health and Welfare, which is accredited by the Ministry of Education, Culture, Sports, Science and Technology, Japan.

\section{Drugs}

4-(2-Diphenyl)- $N$-(1,2,3,4-tetrahydronaphthalen-1-yl)-1-piperazinehexanamide hydrochloride (LP-12; Tocris Bioscience, Minneapolis, MN, USA) was used in the present study as a selective $5-\mathrm{HT}_{7}$ receptor agonist. For experimentation, the LP-12 was dissolved in saline and administered intracerebroventricularly (i.c.v.) in a volume of $4 \mu \mathrm{L} /$ mouse.

\section{Exposure to restraint stress}

Mice were either exposed to repeated restraint stress for 60 or 240 $\mathrm{min}$ /day by being inserted into a syringe $(50 \mathrm{~mL})$ (stressed group) or left in their home cage (non-stressed group) for 1 or 14 days. After the final exposure to restraint stress, emotionality of the mice was estimated using an automatic hole-board apparatus. ${ }^{1-4,21,23} \mathrm{In}$ particular, each mouse was placed in the center of the hole-board and allowed to freely explore the apparatus for $5 \mathrm{~min}$. The exploratory behaviors of mice on the hole-board (i.e. distance moved, number and duration of rearing, number and duration of head-dips, and latency to head-dips) were automatically recorded. In the experiment for examining the effect of LP-12, the drug ( 3 or $10 \mu \mathrm{g} /$ mouse, i.c.v.) or saline was injected immediately after the daily exposure to restraint stress for $240 \mathrm{~min} /$ day.

\section{Automatic hole-board apparatus}

The automatic hole-board apparatus (model ST-1; Muromachi Kikai Co., Ltd., Tokyo, Japan) consisted of a gray box $(50 \times 50 \times 50$ $\mathrm{cm}$ ) with four equidistant holes, each $3 \mathrm{~cm}$ in diameter, in the floor. An infrared beam sensor was installed on the wall to detect the number and duration of rearing and head-dipping behaviors. The distance that mice moved on the hole-board was recorded by an overhead digital video camera; the heads of the mice were painted yellow and the digital video camera followed their center of gravity.

Data from the digital video camera were collected through a custom-designed interface (DVTrack, Muromachi Kikai) as a reflection signal. Head-dipping behaviors were double-checked via an infrared beam sensor and the overhead digital video camera. Thus, head-dipping behavior was counted only when both the head intercepted the infrared beam and the head was detected at the hole by the digital video camera. All of the data were stored in a personal computer and analyzed using analytical software (Comp ACT HBS, Muromachi Kikai).

\section{Western blotting}

After the behavioral experiments, brain regions were quickly removed and homogenized in 6 volumes of ice-cold buffer containing $20 \mathrm{mM}$ Tris-HCI ( $\mathrm{pH}$ 7.4; Wako Pure Chemical Industries, Ltd., Osaka, Japan), $2 \mathrm{mM}$ ethylenediaminetetraacetic acid (EDTA; Wako Pure Chemical), $10 \mathrm{mM}$ ethylene glycol-bis

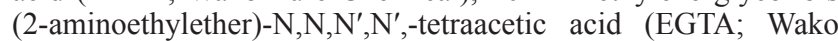
Pure Chemical), $250 \mathrm{mM}$ sucrose (Wako Pure Chemical), 1\% Triton (Calbiochem-Novabiochem, San Diego, CA, USA) and a protease inhibitor cocktail (Complete ${ }^{\circledR}$; Roche Molecular Biochemicals, Mannheim, Germany), and by using a homogenizer (Pellet Pestles $^{\circledR}$ Cordless Motor; Techno Chemical Co., Ltd., Tokyo, Japan). The homogenates were centrifuged at $1,000 \times \mathrm{g}(3,500 \mathrm{rpm})$ for $10 \mathrm{~min}$ at $4{ }^{\circ} \mathrm{C}$, and the supernatants were collected and stored 
(A)

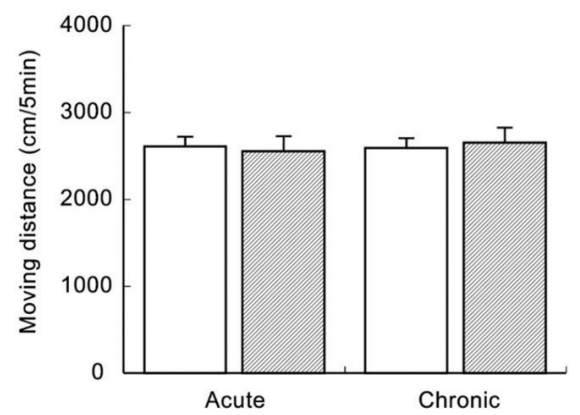

(D)

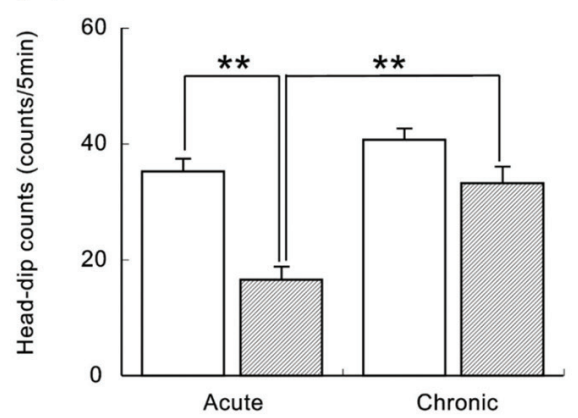

(B)

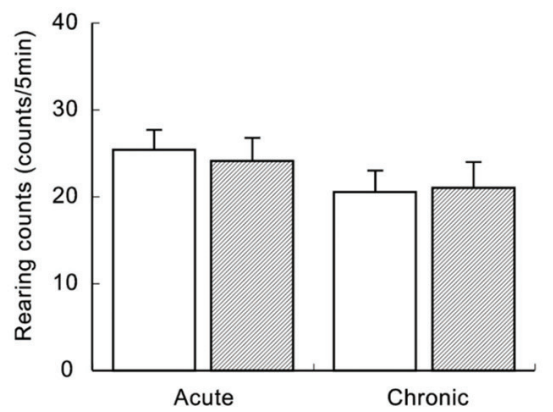

(E)

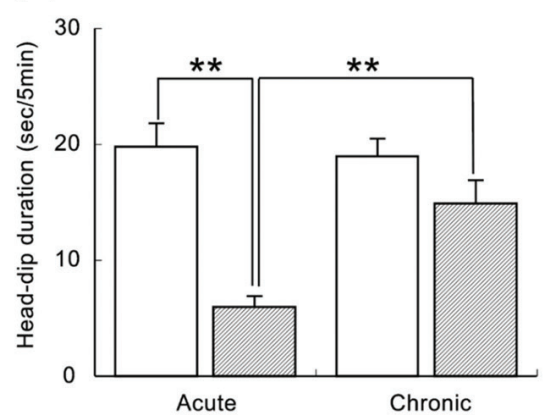

(C)

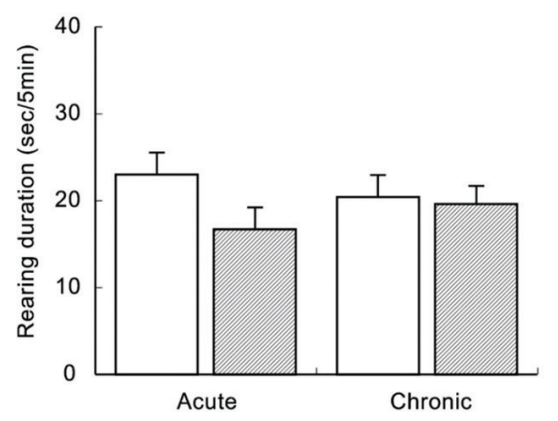

(F)

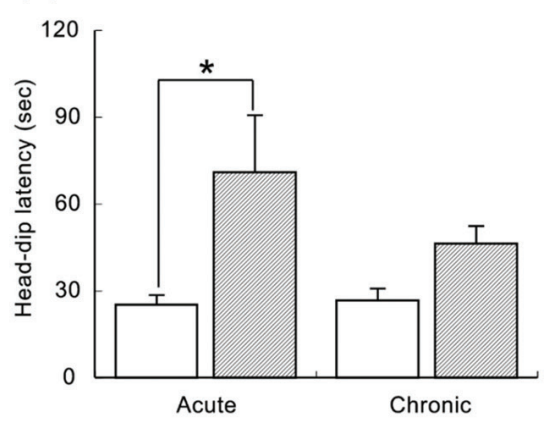

Non-stress $\square$ Stress

Fig. 1. Effects of exposure to adaptable repeated restraint stress on the exploratory behaviors of mice in the hole-board test. A: Moving distance; B: Number of rearing; C: Duration of rearing; D: Number of head-dips; E: Duration of head-dips; F: Latency to head-dips. Each column represents the mean with SEM of $12-16$ mice. ${ }^{*} p<0.05, * * p<0.01$.

as test samples at $-70^{\circ} \mathrm{C}$ for future analysis.

An aliquot of test sample was diluted with an equal volume of electrophoresis sample buffer (Bio-Rad Laboratories, Co., Ltd., Hercules, CA, USA). Proteins were separated by size on $5-20 \%$ SDS-polyacrylamide gradient gel and transferred to a polyvinylidene difluoride (PVDF) membrane (Bio-Rad Laboratories) soaked in $20 \%$ methanol (Wako Pure Chemical) with Tris-glycine buffer (Bio-Rad Laboratories) and by using a semi-dry electrophoretic transfer cell (Bio-Rad Laboratories). In addition, molecular markers (Precision Plus Protein ${ }^{\mathrm{TM}}$ Dual Color Standards; Bio-Rad Laboratories) were loaded in lanes adjacent to sample lanes before the commencement of each run. For the immunoblot detection of $5-\mathrm{HT}_{7}$ receptor, extracellular signal-regulated kinase $1 / 2$ (ERK) or phosphorylated ERK, membranes were blocked in $0.05 \%$ Tween 20 -Tris-buffered saline (TTBS) containing 3\% bovine serum albumin (BSA; Sigma-Aldrich, Co., Ltd., St. Louis, MO, USA) for $1 \mathrm{hr}$ at room temperature with agitation. The membrane was incubated with primary antibody for $5-\mathrm{HT}_{7}$ receptor (1:300 dilution; Imgenex, Co., Ltd., San Diego, CA, USA), ERK (1:1,000; Cell Signaling Technology, Co., Ltd., Danvers, MA, USA) or phosphorylated ERK (1:1,000; Cell Signaling Technology), which were diluted in TTBS containing $3 \%$ BSA overnight at $4{ }^{\circ} \mathrm{C}$. The membranes were washed in TTBS and then incubated for $60 \mathrm{~min}$ at room temperature with horseradish peroxidase-conjugated goat anti-rabbit IgG (1:2,000; Jackson Immunoresearch Laboratories, Co., Ltd., West Grove, PA, USA), which was diluted in TTBS containing 3\% BSA. After this incubation, the membranes were washed in TTBS. The antigen-antibody-peroxidase complex was then finally detected by enhanced chemiluminescence (Santa Cruz Biotechnology, Co., Ltd., Dallas, TX, USA), and scanned, optimized and analyzed by ChemiDoc XRS (Bio-Rad Laboratories). The relative protein levels were compared with the protein level of the appropriate standard (glyceraldehyde 3-phosphate dehydrogenase (GAPDH) for 5-HT 7 receptor blots, total ERK for phosphorylated ERK blots) probed on the same membrane, after stripping of the antibody previously used.

\section{Immunohistochemistry}

In the immunohistochemical analysis, naive (non-stressed) mice were deeply anesthetized with sodium pentobarbital $(70 \mathrm{mg} / \mathrm{kg}$, intraperitoneal (i.p.)) and perfusion-fixed with $4 \%$ paraformaldehyde (Wako Pure Chemical) in PBS. The brains were quickly removed after perfusion, and thick coronal sections, including the hippocampus, were initially dissected using brain blocker. The brain coronal sections were postfixed in $4 \%$ paraformaldehyde for $2 \mathrm{hr}$. After the brains were permeated with $20 \%$ sucrose for 1 day and $30 \%$ sucrose for 2 days, they were frozen in embedding compound (Sakura Finetechnical, Tokyo, Japan) on dry ice and stored at $-30{ }^{\circ} \mathrm{C}$ until use. Frozen $10 \mu \mathrm{m}$-thick coronal sections were cut with a cryostat (Sakura Finetechnical) and thaw-mounted on amino silane-coated glass slides (Matsunami Glass Ind., Ltd., Osaka, Japan).

The mounted brain sections were incubated with $10 \%$ normal goat serum in ice-cold PBS for 60 min to block the binding of 
(A)

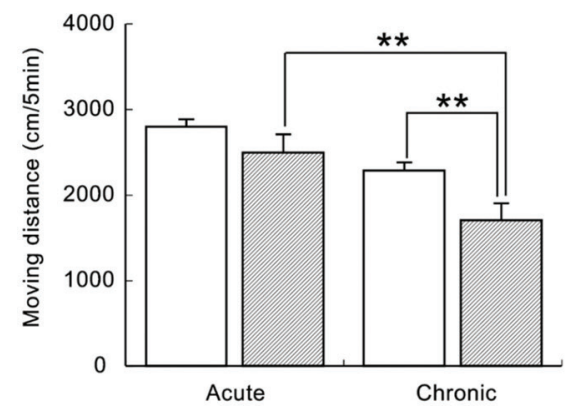

(D)

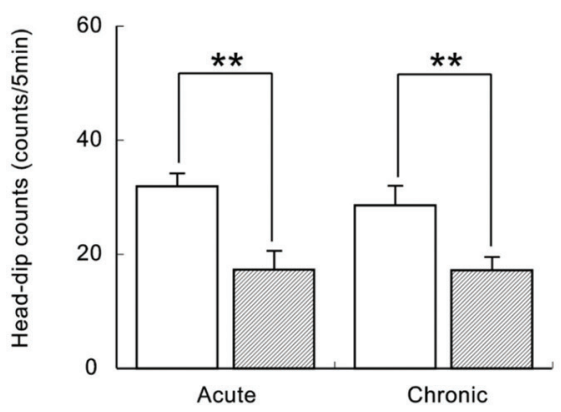

(B)

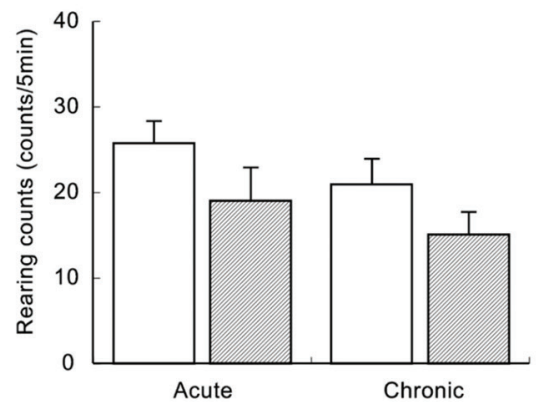

(E)

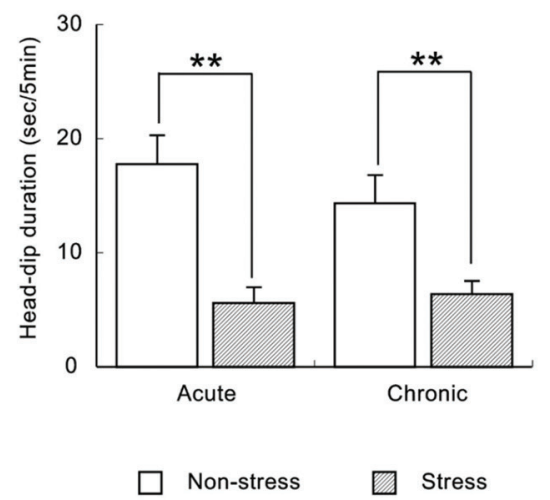

(C)

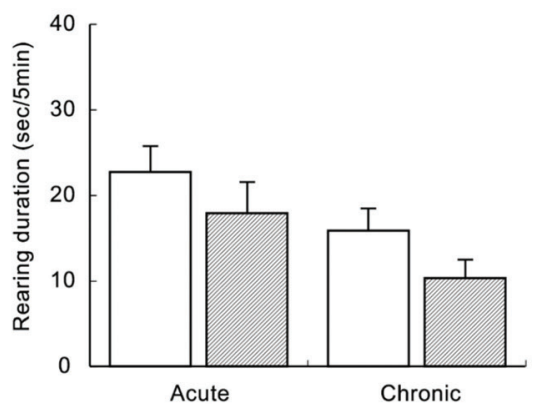

$(\mathrm{F})$

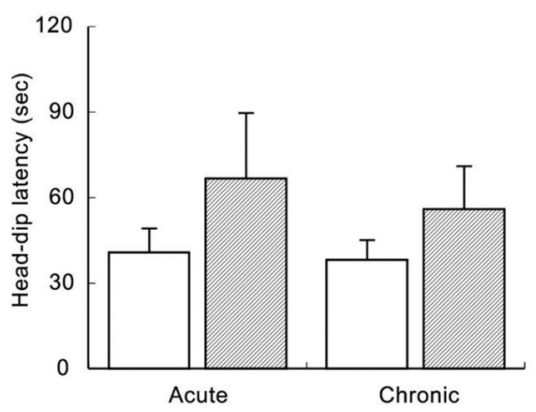

Fig. 2. Effects of exposure to unadaptable repeated restraint stress on the exploratory behaviors of mice in the hole-board test. A: Moving distance; B: Number of rearing; C: Duration of rearing; D: Number of head-dips; E: Duration of head-dips; F: Latency to head-dips. Each column represents the mean with SEM of 8-15 mice. ${ }^{* *} p<0.01$.

nonspecific antibody. Each primary antibody was diluted in PBS containing normal goat serum (1:100 5-HT 7 receptor (Imgenex), 1:100 p-ERK (Cell Signaling Technology)) and incubated for 2 days at $4{ }^{\circ} \mathrm{C}$. The samples were then rinsed with PBS and incubated with the appropriate secondary antibody conjugated with Alexa 488 and Alexa 546 (1:500) for $2 \mathrm{~h}$ at room temperature. The slides were then cover-slipped with PermaFluor aqueous mounting medium (Immunon, Pittsburgh, PA, USA). Fluorescence immunolabeling was detected using a confocal laser-scanning microscope (FV1000; Olympus Optical, Tokyo, Japan).

\section{Statistical analysis}

Data are presented as mean \pm S.E.M. Treatment effects were compared using one-way analysis of variance (ANOVA) followed by the Student-Newman-Keuls multiple comparisons post-hoc test. Probability values of less than 0.05 were accepted as significant.

\section{Results}

\section{Effects of exposure to repeated restraint stress on emotionality of mice as estimated by the hole-board test}

The effects of exposure to repeated restraint stress on emotionality of mice as estimated by the hole-board test are shown in Figures 1 and 2. A single exposure to restraint stress for $60 \mathrm{~min}$ induced significant decreases in the number and duration of headdipping behaviors (Fig. 1D and 1E; $p<0.01$ ) as well as an increase in latency to head-dips (Fig. 1F; $p<0.05$ ) in the hole-board test. These emotional stress responses were not observed in mice that were exposed to the same duration of restraint stress repeatedly once a day for 14 days (Fig. 1D, 1E and $1 F$ ). In contrast, mice that were exposed to restraint stress daily for $240 \mathrm{~min} /$ day for 14 days continued to show a significant decrease in the number and duration of head-dipping behaviors (Fig. 2D and 2E; $p<0.01$ ). The distance mice moved was also significantly decreased (Fig. $2 \mathrm{~A} ; p<0.01)$.

Changes in the expression of 5-HT, receptor in brain regions of mice induced by exposure to adaptable or unadaptable stress

The changes in expression of $5-\mathrm{HT}_{7}$ receptor in brain regions of mice induced by exposure to adaptable or unadaptable stress are shown in Figure 3. Western blot analysis revealed two bands with apparent molecular masses of approximately 45 and $50 \mathrm{kDa}$ in extracts of hippocampal tissue (Fig. 3A). Therefore, expression levels of $5-\mathrm{HT}_{7}$ receptor were assessed in terms of the combination of two molecules. These signals were standardized by normalization with the signal for GAPDH. The expression of 5- $\mathrm{HT}_{7}$ receptor was significantly increased in both the frontal cortex (Fig. 3B; $p<$ 0.05 ) and hippocampus (Fig. 3C; $p<0.05$ ) of mice that had been chronically exposed to adaptable stress (60 $\mathrm{min} /$ day for 14 days), although such changes in the expression levels were not observed in the other brain regions examined ( $\%$ of control: amygdala, 
(A)

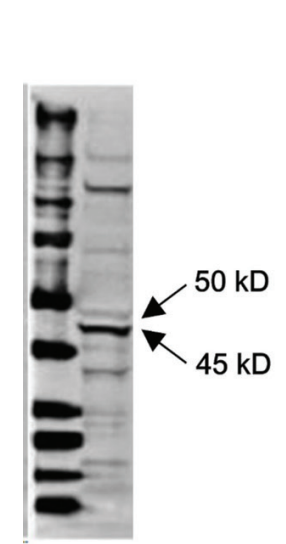

(B) 5- $\mathrm{HT}_{7}$ receptor GAPDH
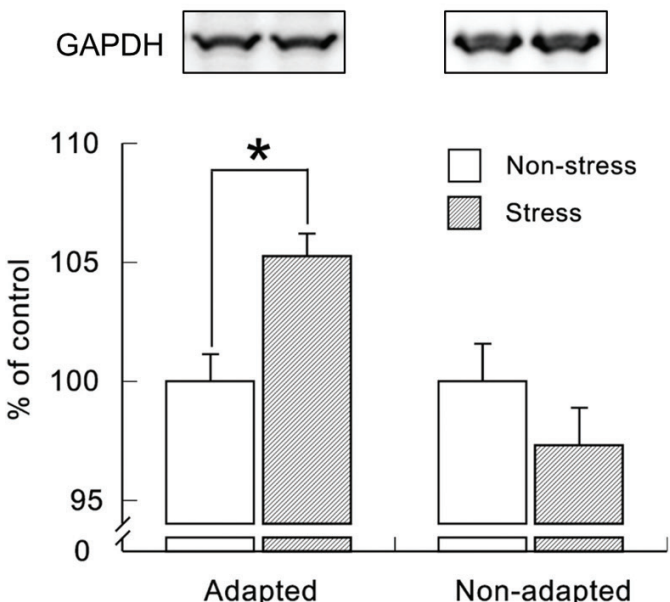

(C)
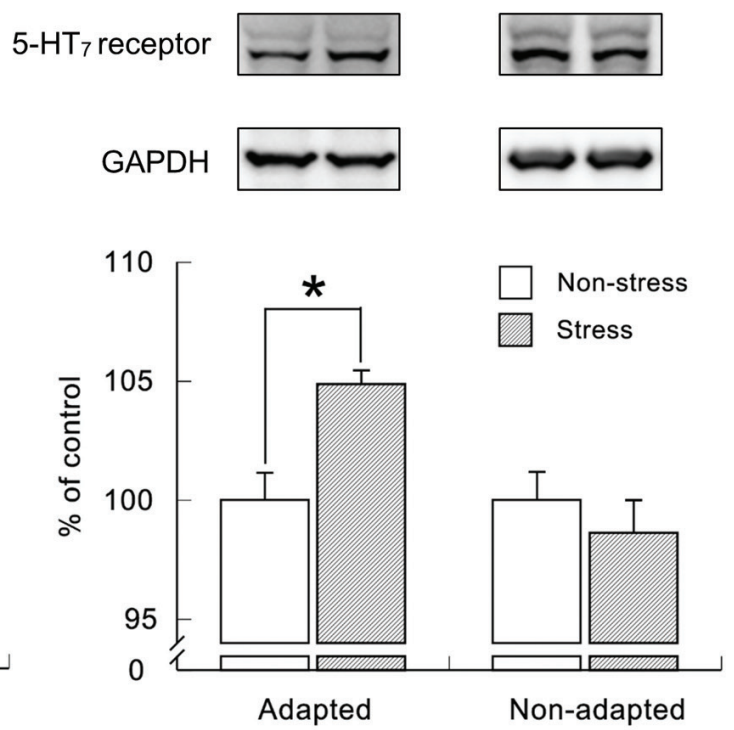

Fig. 3. Changes in 5-HT 7 receptor expression in the frontal cortex and hippocampus of mice exposed to adaptable or unadaptable stress. A: Immunoblots of hippocampal tissues showing $5-\mathrm{HT}_{7}$ receptor. $\mathrm{B}, \mathrm{C}$ : The expression level of $5-\mathrm{HT}_{7}$ receptor was assessed in terms of the combination of two molecules in the same tissue: frontal cortex (B) and hippocampus (C). The expression is expressed as the percentage of values measured in the corresponding nonstressed group. Each column represents the mean with SEM of 8-10 mice. ${ }^{*} p<0.05$.

non-stressed: $100 \pm 1.5$, stressed: $99.3 \pm 1.3$; hypothalamus, nonstressed: $100 \pm 0.7$, stressed: $97.9 \pm 2.2$; midbrain, non-stressed: $100 \pm 1.6$, stressed: $102.4 \pm 4.3)$. In contrast, the expression of $5-\mathrm{HT}_{7}$ receptor in both the frontal cortex (Fig. 3B) and hippocampus (Fig. 3C) was unchanged in mice that had been chronically exposed to unadaptable stress ( $240 \mathrm{~min} /$ day for 14 days $)$.

\section{Localization of 5-HT, receptor and phosphorylated ERK in the anterior cingulate cortex and hippocampal CA2/CA3 subfields in mice}

The localization of $5-\mathrm{HT}_{7}$ receptor and phosphorylated ERK in the anterior cingulate cortex and hippocampal CA2/CA3 subfields in mice is shown in Figure 4. Immunohistochemistry was used to localize $5-\mathrm{HT}_{7}$ receptor and phosphorylated ERK. Abundant immunoreactivity for $5-\mathrm{HT}_{7}$ receptor and phosphorylated ERK was observed in the anterior cingulate cortex (Fig. 4A) and hippocampal CA2/CA3 subfields (Fig. 4B). Importantly, the expression of 5- $\mathrm{HT}_{7}$ receptor and phosphorylated ERK show almost complete overlap in both brain regions.

Changes in ERK phosphorylation in the frontal cortex and hippocampus of mice induced by exposure to adaptable or unadaptable stress

The changes in ERK phosphorylation in the frontal cortex and hippocampus of mice induced by exposure to adaptable or unadaptable stress are shown in Figure 5. To evaluate ERK activation, the phosphorylated ERK levels were normalized with respect to the total ERK levels in the same membranes. ERK phosphorylation closely paralleled changes in 5-HT receptor expression in stressadaptive and -maladaptive mice; ERK phosphorylation was significantly increased in the frontal cortex (Fig. $5 \mathrm{~A} ; p<0.01$ ) and hippocampus (Fig. 5B; $p<0.01$ ) of mice that had been chronically exposed to adaptable stress (60 $\mathrm{min} /$ day for 14 days). In contrast, such changes in the phosphorylation levels of ERK were not observed in mice that had been chronically exposed to unadaptable stress (240 min/day for 14 days) (Fig. 5A and 5B).

\section{Effects of LP-12 on the emotional abnormality in mice induced by exposure to unadaptable stress}

The effects of LP-12 on the emotional abnormality in mice induced by exposure to unadaptable stress are shown in Figure 6. Repeated exposure to restraint stress for $240 \mathrm{~min} /$ day for 14 days induced significant decreases in the number and duration of headdipping behaviors in the hole-board test (Fig. 6D and 6E; $p<0.01$ ). The decrease in head-dipping behavior was dose-dependently and significantly inhibited by chronic treatment with LP-12 (3 and 10 $\mu \mathrm{g} /$ mouse, i.c.v.) immediately after the daily exposure to restraint stress (Fig. 6D and 6E; $p<0.05$ ).

\section{Discussion}

The hole-board test offers a simple method for measuring the response of an animal to an unfamiliar environment. In the holeboard test, a pronounced inhibition of head-dipping behavior is observed in rats or mice following exposure to stress stimuli. 22,25 We also previously reported that either treatment with benzodiazepine anxiogenics or exposure to acute restraint stress produced a decrease in head-dipping behavior in mice. ${ }^{1-4,21,23}$ These findings indicate that head-dipping behavior in the hole-board test is a good index for evaluating emotionality of mice. In the present study, a single exposure to restraint stress for 60 min produced a decrease in the number and duration of head-dipping behaviors of mice in the hole-board test, and these acute emotional responses were re- 
(A)
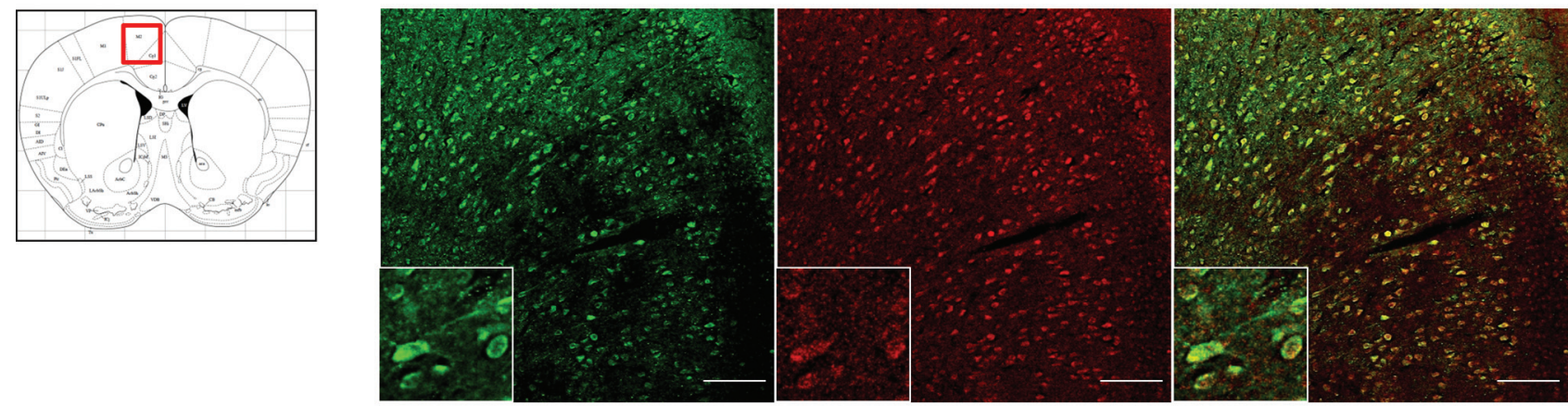

(B)

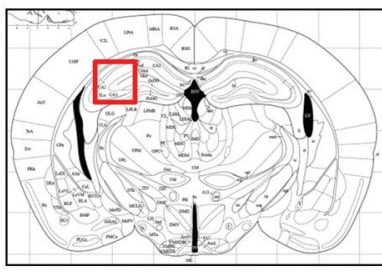

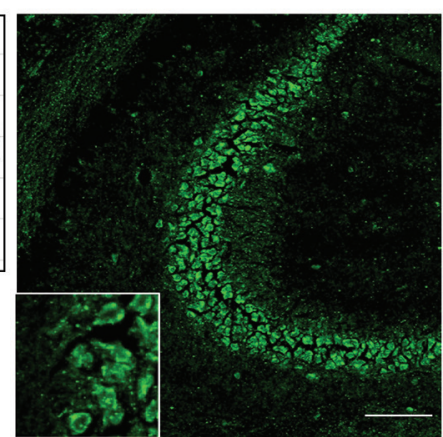

$5-\mathrm{HT}_{7}$ receptor

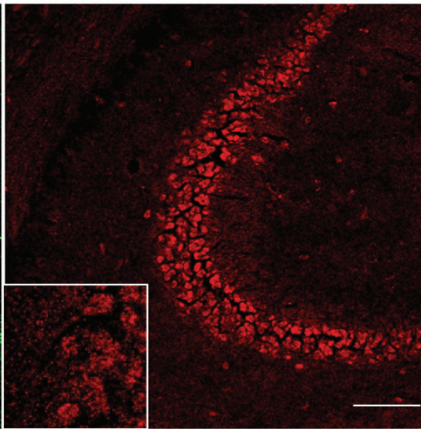

Phosphorylated ERK

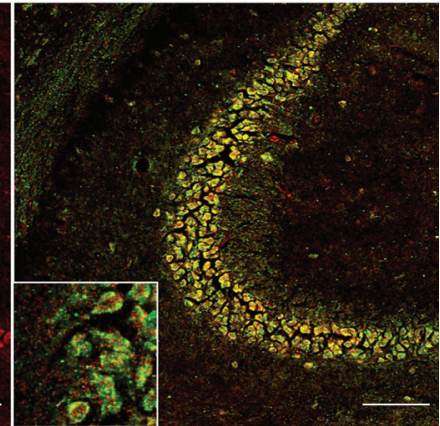

Merge

Scale bar: $100 \mu \mathrm{m}$

Fig. 4. Localization of $5-\mathrm{HT}_{7}$ receptor and phosphorylated ERK in the anterior cingulate cortex (A) and hippocampal CA2/CA3 subfields (B) in naive (nonstressed) mice. The $5-\mathrm{HT}_{7}$ receptor (green) and phosphorylated ERK (red) are almost co-localized. High-magnification images suggest that the 5-HT, receptor is localized in the membrane of phosphorylated ERK-positive cells. Scale bars: $100 \mu \mathrm{m}$.

covered by exposure to repeated restraint stress for $60 \mathrm{~min} /$ day for 14 days. In contrast, this development of stress adaptation was not observed in mice that had been exposed to repeated restraint stress for $240 \mathrm{~min} /$ day for 14 days, i.e. they continued to show a decrease in head-dipping behavior in the hole-board test. These findings are in good agreement with our previous report, ${ }^{21}$ and confirm that stress-adaptive and -maladaptive models can be created in mice by repeatedly exposing them to different degrees of restraint stress. Thus, in the subsequent studies, we used the stress-adaptive and -maladaptive mice to examine whether brain $5-\mathrm{HT}_{7}$ receptors are involved in the development of stress adaptation.

Several splice variants of human $\left(5-\mathrm{HT}_{7(\mathrm{a} / \mathrm{b} / \mathrm{d})}\right)$, mouse $\left(5-\mathrm{HT}_{7(\mathrm{a} /}\right.$ $\mathrm{b} / \mathrm{c})$ and rat $\left(5-\mathrm{HT}_{7(\mathrm{a} / \mathrm{b} / \mathrm{c} / \mathrm{e})}\right)$ receptors have been identified. When expressed in cell lines they display similar pharmacological and functional characteristics, and also a similar tissue distribution. ${ }^{27-29}$ In western blot analysis using a specific antibody raised against a sequence that is identical for all human receptor splice variants, two bands were detected in various types of cells, in particular the Chinese hamster ovary (commonly known as CHO) cells stably transfected with the human $5-\mathrm{HT}_{7(\mathrm{a})}$ receptor cDNA, the human glioblastoma cell lines and the human microglial MC-3 cell line, with apparent molecular masses of approximately 45 and $50 \mathrm{kDa} .^{30,31}$ The $45-50 \mathrm{kDa}$ range corresponds to the anticipated molecular mass of the $5-\mathrm{HT}_{7}$ receptor, perhaps with different degrees of glycosylation and/or phosphorylation. ${ }^{32}$

Consistent with these previous reports, in the present study, western blot analysis using the same specific antibody confirmed two bands with molecular masses of approximately 45 and $50 \mathrm{kDa}$ in extracts of mouse hippocampal tissue. Thus, the expression levels of 5-HT 7 receptor were assessed in terms of the combination of two molecules. The expression of $5-\mathrm{HT}_{7}$ receptor was significantly increased in the frontal cortex and hippocampus of mice that had been chronically exposed to adaptable stress $(60 \mathrm{~min} /$ day for 14 days), while such changes were not observed in other brain regions, including the amygdala, hypothalamus and midbrain, which may play a role in the regulation of emotion. In contrast, the expression of $5-\mathrm{HT}_{7}$ receptor in the frontal cortex and hippocampus was unchanged in mice that had been chronically exposed to unadaptable stress (240 $\mathrm{min} /$ day for 14 days). These findings suggest that the up-regulation of cortical and/or hippocampal 5- $\mathrm{HT}_{7}$ receptors may be involved in the development of stress adaptation.

$5-\mathrm{HT}_{7}$ receptor activation activates adenylyl cyclase signaling and consequently the conversion of ATP to cAMP through coupling to Gas. ${ }^{6}$ ERK belongs to a family of mitogen-activated protein (MAP) kinases that integrate signals received by membrane growth factor and $\mathrm{G}$ protein-coupled receptors and transfer them to the nucleus. ${ }^{33}$ A growing body of evidence suggests that the ERKmediated signaling pathway in the brain is essential for stress-related mood regulation. ${ }^{34}$ It has been found that $5-\mathrm{HT}_{7}$ receptors, expressed by cultured rat hippocampal neurons as well as human embryonic kidney (commonly known as HEK) 293 cells, are associated with the stimulation of ERK. ${ }^{35-37}$ 
(A)
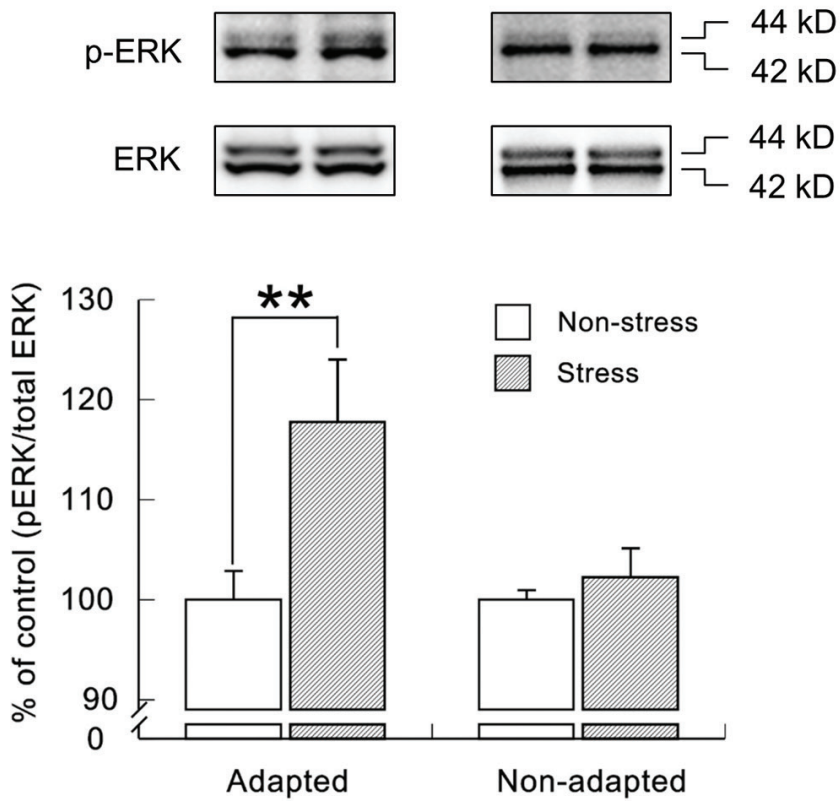

(B)

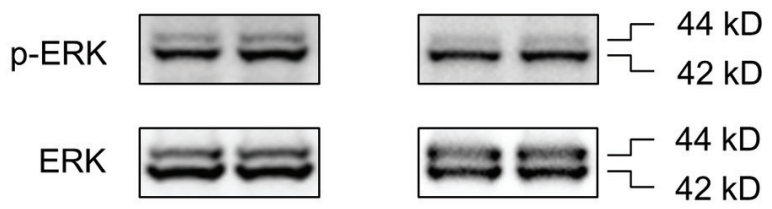

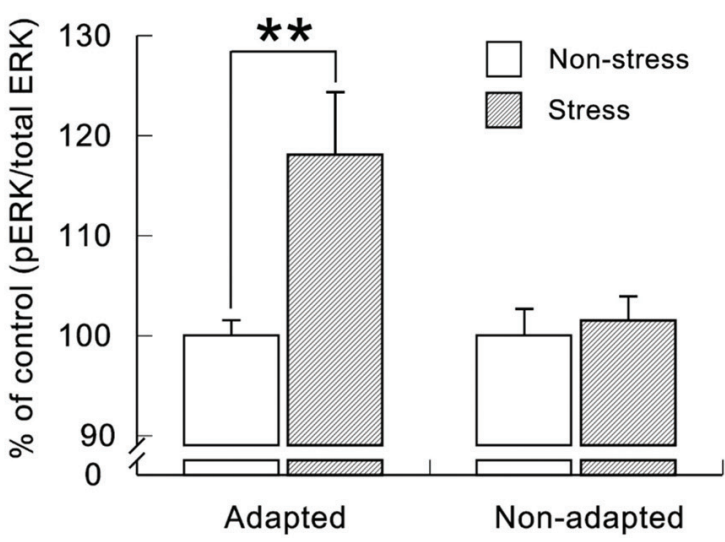

Fig. 5. Changes in ERK phosphorylation in the frontal cortex and hippocampus of mice exposed to adaptable or unadaptable stress. A, B: The level of ERK phosphorylation was measured as the intensity of phosphorylated ERK normalized with respect to that of unphosphorylated ERK in the same tissue: frontal cortex (A) and hippocampus (B). ERK phosphorylation is expressed as the percentage of values measured in the corresponding non-stressed group. Each column represents the mean with SEM of $8-10$ mice. $* * p<0.01$.

In the present study, an immunohistochemical analysis revealed the co-localization of immunoreactivity of $5-\mathrm{HT}_{7}$ receptor and phosphorylated ERK in the anterior cingulate cortex and hippocampal CA2/CA3 subfields, indicating that ERK plays an important role in intracellular signaling via the $5-\mathrm{HT}_{7}$ receptor. More importantly, western blot analysis showed that ERK phosphorylation closely paralleled changes in 5-HT receptor expression in stress-adaptive and -maladaptive mice. ERK phosphorylation was significantly increased in the frontal cortex and hippocampus of mice that had been chronically exposed to adaptable stress. In contrast, such changes in the phosphorylation levels of ERK were not observed in mice that had been chronically exposed to unadaptable stress. These findings suggest that a cortical and/or hippocampal $5-\mathrm{HT}_{7}$ receptor-ERK pathway may play an important role in the development of stress adaptation.

Finally, we examined the effect of LP-12, a selective $5-\mathrm{HT}_{7}$ receptor agonist, on the abnormality of stress-maladaptive mice. It has been reported that LP-12 has high affinity $(\mathrm{Ki}=0.13 \mathrm{nM})$ as well as high selectivity for the $5-\mathrm{HT}_{7}$ receptor over the $5-\mathrm{HT}_{1 \mathrm{~A}}$, $5-\mathrm{HT}_{2 \mathrm{~A}}$ and $\mathrm{D}_{2}$ receptors (468-, 11,262- and 1,723-fold, respectively), which represent the receptors that may interfere with the evaluation of actions on emotionality mediated by $5-\mathrm{HT}_{7}$ receptor. ${ }^{38}$ In the hole-board test, the significant decreases in both the number and duration of head-dipping behaviors of mice induced by exposure to unadaptable stress were dose-dependently and significantly inhibited by chronic treatment with LP-12 immediately after daily exposure to stress. This result supports the findings in the present biochemical study suggesting that activation of the $5-\mathrm{HT}_{7}$ receptor may be critical for the development of stress adaptation.

Recently, several reports have suggested that a $5-\mathrm{HT}_{7}$ receptor agonist might be a novel therapeutic strategy for neuropsychiatric disorders. Activation of $5-\mathrm{HT}_{7}$ receptors by agonists was shown to reverse metabotropic glutamate receptor-mediated long-term depression and to correct a synaptic malfunction in Fmrl knock-out mice, which is a mouse model of Fragile X Syndrome, the most common form of inherited intellectual disability associated with mood disorders. ${ }^{39,40}$ In Rett Syndrome, a disorder in which severe symptoms affect cognitive, sensory, emotional, motor and autonomic functions, 5- $\mathrm{HT}_{7}$ receptor agonist was shown to ameliorate the deficits in motor coordination, spatial reference memory, and hippocampal synaptic plasticity in a mice model ${ }^{41}$ Thus, the activation of $5-\mathrm{HT}_{7}$ receptor appears to restore synaptic plasticity, suggesting that agonists of this receptor might be used as novel pharmacological tools in both diseases. The present findings also raise the possibility that a $5-\mathrm{HT}_{7}$ receptor agonist might be effective for the clinical treatment of mental illness that results from maladaptive coping with stressful situations, such as adjustment disorder.

Although it is well-recognized that modulation of the 5-HT, receptor affects mood regulation, the present findings somewhat contradict previous reports that the blockade of 5- $\mathrm{HT}_{7}$ receptor exerts anxiolytic and antidepressive effects. ${ }^{10-13}$ While the reason for this discrepancy is not fully understood, differences in the type and duration of stress exposure may be involved. The present study used an animal model of exposure to chronic restraint stress, whereas all of the above-mentioned previous findings were obtained from behavioral paradigms involving acute stress, including forced swimming, tail suspension and the elevated plus-maze test. Therefore, the present findings imply that brain $5-\mathrm{HT}_{7}$ receptors might play multiple roles in the pathophysiology or treatment of stress-related mood disorders. In support of this hypothesis, it has been reported that chronic treatment with imipramine (a tricyclic antidepressant) or citalopram (a selective serotonin reuptake blocker) decreased the reactivity of hippocampal 5- $\mathrm{HT}_{7}$ receptors, while electroconvulsive shocks, which are known to be effective for treatment-resistant major depressive disorder, increased the 
(A)

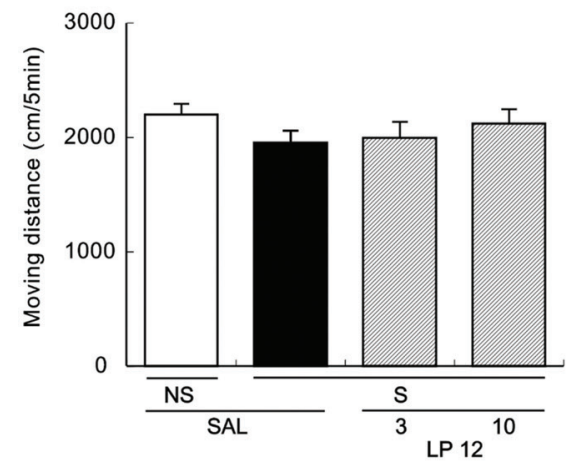

(D)

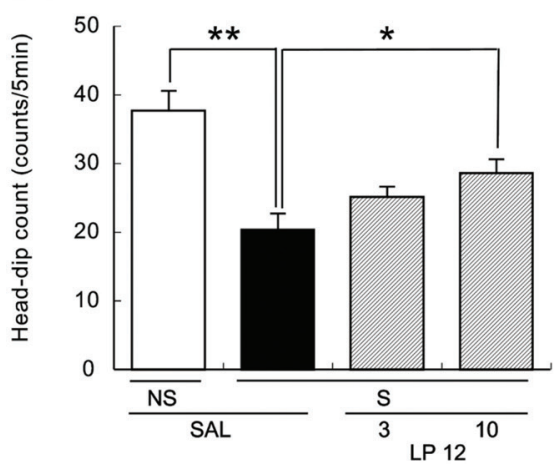

(B)

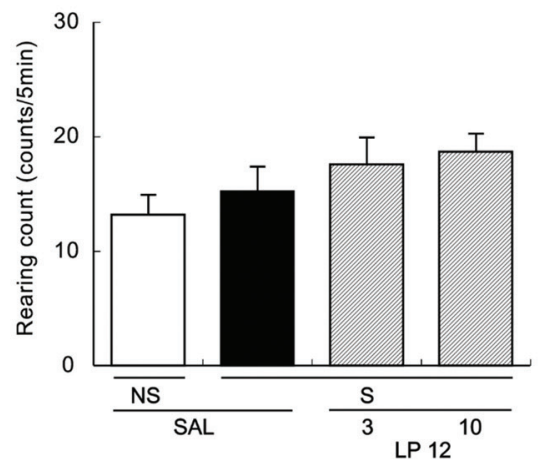

(E)

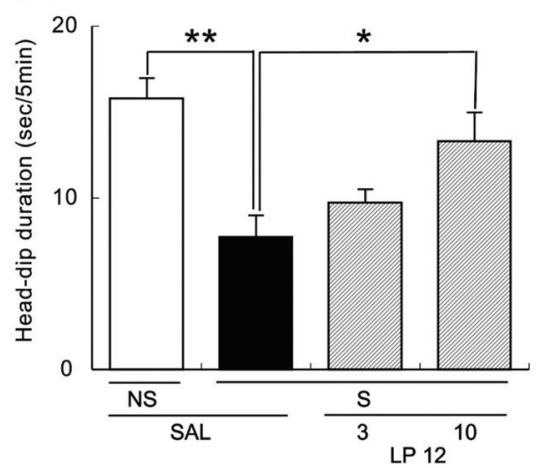

(C)

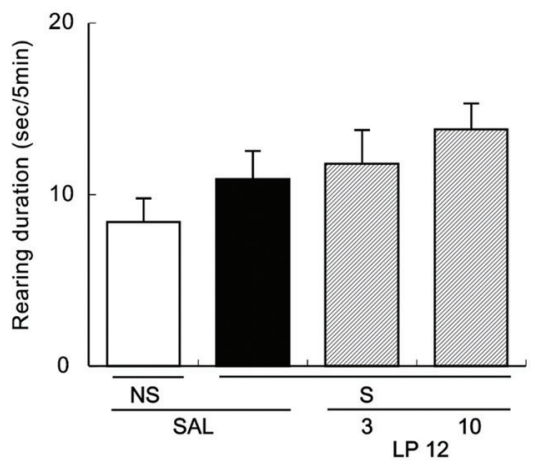

$(\mathrm{F})$

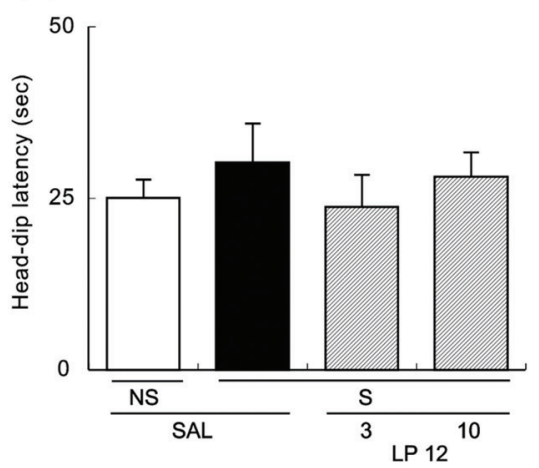

Fig. 6. Effects of LP-12 on the changes in exploratory behaviors of mice in the hole-board test. A: Moving distance; B: Number of rearing; C: Duration of rearing; D: Number of head-dips; E: Duration of head-dips; F: Latency to head-dips. Mice were either exposed to repeated restraint stress for 240 min/day (stressed group: S) or left in their home cage (non-stressed group: NS) for 14 days. LP-12 (3 or $10 \mu \mathrm{g} / \mathrm{mouse}$, i.c.v.) or saline (SAL) was injected immediately after the daily exposure to restraint stress. Each column represents the mean with SEM of $16-19$ mice. ${ }^{*} p<0.05, * * p<0.01$.

\section{5- $\mathrm{HT}_{7}$ receptor-dependent response in the hippocampus. ${ }^{42,43}$}

Although the distinct mechanisms underlying the role of brain $5-\mathrm{HT}_{7}$ receptor in stress adaptation are still unclear, one possible explanation is that the modulation of neuronal plasticity and morphology might be involved. For example, it has recently been reported that treatment with $5-\mathrm{HT}_{7}$ receptor agonist can increase the expression and phosphorylation of tropomyosin-related kinase $\mathrm{B}$ (TrkB) receptor. ${ }^{44}$ TrkB is a receptor of brain-derived neurotrophic factor (BDNF), a member of the neurotrophin family of growth factors that are involved in both neuronal plasticity and remodeling of neuronal morphology. Thus, these findings suggest that the BDNF signaling may be enhanced by $5-\mathrm{HT}_{7}$ receptor activation. Another study showed direct evidence that $5-\mathrm{HT}_{7}$ receptor modulated the neuronal morphology, in that neurite outgrowth was enhanced by the stimulation of $5-\mathrm{HT}_{7}$ receptor via several signal transduction pathways, such as mammalian target of rapamycin (mTOR), cell division cycle 42 (Cdc42), cyclin-dependent kinase 5 (Cdk5) and ERK, and all of these molecules converge to modulate cytoskeletal reorganization. ${ }^{45}$ More recently, it has been reported that $5-\mathrm{HT}_{7}$ receptor activation increased CAMP and relative phosphorylated cAMP response element-binding protein (CREB) levels and also increased phosphorylation of the GluA1 AMPA receptor subunit in hippocampal neurons; moreover, these biochemical findings were supported by electrophysiological findings in the hippocampus that showed AMPA receptor-mediated neurotransmission was enhanced by stimulation of the $5-\mathrm{HT}_{7}$ receptor. ${ }^{46}$ Importantly, these $5-\mathrm{HT}_{7}$ receptor-mediated molecular and cellular mechanisms that have been shown to be involved in neuronal plasticity and mor- phology are consistent with the new insights into neurobiology of stress and mood disorders. ${ }^{47}$ Taken together, these findings suggest that further detailed studies focused on neuronal plasticity and morphology, which may be modulated by the $5-\mathrm{HT}_{7}$ receptor, may be useful for understanding the mechanisms of stress adaptation.

In the context of the present findings, we need further investigation in future studies. First, in order to confirm the significant role of $5-\mathrm{HT}_{7}$ receptor in the development of stress adaptation, the influence of a $5-\mathrm{HT}_{7}$ receptor antagonist in stress-adaptive mice need to be investigated. Indeed, we recently carried out a part of such a study, and obtained a preliminary finding that i.c.v. treatment with the $5-\mathrm{HT}_{7}$ receptor antagonist SB269970 immediately after daily exposure to adaptable stress disturbed the development of stress adaptation and induced abnormality of the anxiety sensitivity in the elevated plus-maze test (i.e. excessive increase in time spent in open-arm together with decrease in stretched attend posture; unpublished observation). Second, because LP-12 inhibited the decrease in the emotionality of stress-maladaptive mice, it would be more informative to examine the change in ERK activity induced by LP-12. We speculate that LP-12 may show an effect to increase ERK phosphorylation in the frontal cortex and hippocampus of stress-maladaptive mice. These future studies may be helpful for enhancing the value of the present findings.

In conclusion, the present study demonstrated that $5-\mathrm{HT}_{7}$ receptor expression as well as ERK phosphorylation were increased in stress-adapted, but not -maladapted, mice. Furthermore, decreases in emotional behaviors of stress-maladapted mice induced by exposure to unadaptable stress were alleviated by the pharmacologi- 
cal activation of the 5- $\mathrm{HT}_{7}$ receptor. The present findings suggest that the brain's 5- $\mathrm{HT}_{7}$ receptor-ERK system may play an important role in the formation of stress adaptation. Furthermore, stimulation of $5-\mathrm{HT}_{7}$ receptors may have a beneficial effect on stress adaptation and alleviate emotional abnormality under conditions of excessive stress. The $5-\mathrm{HT}_{7}$ receptor may represent a promising target for innovative therapeutical strategies in stress-related neuropsychiatric disorders.

\section{Acknowledgments}

This work was supported in part by a grant from the Ministry of Education, Culture, Sports, Science and Technology of Japan (KAKENHI 19790069).

\section{Conflict of interest}

The authors have no conflict of interests related to this publication.

\section{Author contributions}

Designing research (KT, MT, HT), performing research (KT, MT, $\mathrm{KM}$ ), analyzing data (KT, MT, KM), writing paper (KT, MT), proofreading (HT).

\section{References}

[1] Tsuji M, Takeda H, Matsumiya $\mathrm{T}$. Different effects of $5-\mathrm{HT}_{1 \mathrm{~A}}$ receptor agonists and benzodiazepine anxiolytics on the emotional state of naive and stressed mice: a study using hole-board test. Psychopharmacology (Berl) 2000;152(2):157-166. doi:10.1007/s002130000514.

[2] Tsuji M, Takeda H, Matsumiya T. Protective effects of $5-\mathrm{HT}_{1 \mathrm{~A}}$ receptor agonists against emotional changes produced by stress stimuli are related to their neuroendocrine effects. $\mathrm{Br} J$ Pharmacol 2001;134(3):585-595. doi:10.1038/sj.bjp.0704276.

[3] Tsuji M, Takeda H, Matsumiya T. Brain $5-\mathrm{HT}_{1 \mathrm{~A}}$ receptors as important mediators in the development of stress adaptation. Curr Neuropharmacol 2003;1(4):315-324. doi:10.2174/1570159033477044.

[4] Tsuji M, Miyagawa K, Takeda H. Epigenetic regulation of resistance to emotional stress: possible involvement of $5-\mathrm{HT}_{1 \mathrm{~A}}$ receptor-mediated histone acetylation. J Pharmacol Sci 2014;125(4):347-354. doi:10.1254/jphs.14R07CP.

[5] Hoyer D, Hannon JP, Martin GR. Molecular, pharmacological and functional diversity of 5-HT receptors. Pharmacol Biochem Behav 2002;71:533-554. doi:10.1016/S0091-3057(01)00746-8.

[6] Ruat M, Traiffort E, Leurs R, Tardivel-Lacoomebe J, Diaz J, Arrang JM, et al. Molecular cloning, characterization, and localization of a highaffinity serotonin receptor $\left(5-\mathrm{HT}_{7}\right)$ activating cAMP formation. Proc Natl Acad Sci USA 1993;90(18):8547-8551.

[7] Shen Y, Monsma Jr FJ, Metcalf MA, Jose PA, Hamblin MW, Sibley DR. Molecular cloning and expression of a 5-hydroxytrypamine7 serotonin receptor subtype. J Biol Chem 1993;268(24):18200-18204.

[8] Gustafson EL, Durkin MM, Bard JA, Zgombick J, Branchek TA. A receptor autoradiographic and in situ hybridization analysis of the distribution of the $5-\mathrm{HT}_{7}$ receptor in rat brain. $\mathrm{Br} \mathrm{J}$ Pharmacol 1996;117(4):657-666. doi:10.1111/j.1476-5381.1996.tb15241.x.

[9] Neumaier JF, Sexton TJ, Yracheta J, Diaz AM, Brownfield M. Localization of $5 \mathrm{HT}_{7}$ receptors in rat brain by immunocytochemistry, in situ hybridization, and agonist stimulated cFos expression. J Chem Neuroanat 2004;21(1):63-73. doi:10.1016/S0891-0618(00)00092-2.

[10] Wesołowska A, Nikiforuk A, Stachowicz K, Tatarczyńska E. Effect of the selective 5- $\mathrm{HT}_{7}$ receptor antagonist SB 269970 in animal mod- els of anxiety and depression. Neuropharmacology 2006;51(3):578586. doi:10.1016/j.neuropharm.2006.04.017.

[11] Wesołowska A, Nikiforuk A, Stachowicz K. Potential anxiolytic and antidepressive effects of the selective $5-\mathrm{HT}_{7}$ receptor antagonist $\mathrm{SB}$ 269970 after intrahippocampal administration to rats. Eur J Pharmacol 2006;553(1-3):185-190. doi:10.1016/j.ejphar.2006.09.064.

[12] Wesołowska A, Tatarczyńska E, Nikiforuk A, Chojnacka-Wójcik E. Enhancement of the anti-immobility action of antidepressants by a selective $5-\mathrm{HT}_{7}$ receptor antagonist in the forced swimming test in mice. Eur J Pharmacol 2007;555(1):43-47. doi:10.1016/j. ejphar.2006.10.001.

[13] Bonaventure P, Kelly L, Aluisio L, Shelton J, Lord B, Galici R, et al. Selective blockade of 5-hydroxytryptamine $(5-\mathrm{HT})_{7}$ receptors enhances 5-HT transmission, antidepressant-like behavior, and rapid eye movement sleep suppression induced by citalopram in rodents. J Pharmacol Exp Ther 2007;321(2):690-698. doi:10.1124/jpet.107.119404.

[14] Renner U, Zeug A, Woehler A, Niebert M, Dityatev A, Dityateva G, et al. Heterodimerization of serotonin receptors $5-\mathrm{HT}_{1 \mathrm{~A}}$ and $5-\mathrm{HT}$ differentially regulates receptor signalling and trafficking. J Cell Sci 2012;125(Pt10):2486-2499. doi:10.1242/jcs.101337.

[15] Kennett GA, Dickinson SL, Curzon G. Enhancement of some 5-HTdependent behavioral responses following repeated immobilization in rats. Brain Res 1985;330(2):253-263. doi:10.1016/00068993(85)90684-5.

[16] Kennett GA, Dickinson SL, Curzon G. Central serotonergic responses and behavioral adaptation to repeated immobilization: The effect of the corticosterone synthesis inhibitor metyrapone. Eur J Pharmacol 1985;119(3):143-152. doi:10.1016/0014-2999(85)90290-0.

[17] Kennett GA, Chaouloff F, Margaret M, Curzon G. Female rats are more vulnerable than males in an animal model of depression: The possible role of serotonin. Brain Res 1986;382(2):416-421. doi:10.1016/0006-8993(86)91355-7.

[18] Ohi K, Mikuni M, Takahashi K. Stress adaptation and hypersensitivity in 5-HT neuronal system after repeated foot shock. Pharmacol Biochem Behav 1989;34(3):603-608. doi:10.1016/00913057(89)90566-2.

[19] Haleem DJ, Parveen T. Brain regional serotonin synthesis following adaptation to repeated restraint. Neuroreport 1994;5(14):17851788.

[20] Haleem DJ. Adaptation to repeated restraint stress in rats: Failure of ethanol-treated rats to adapt in the stress schedule. Alcohol Alcohol 1996;31(5):471-477. doi:10.1093/oxfordjournals.alcalc.a008181.

[21] Tsuji M, Takeuchi T, Miyagawa K, Ishii D, Imai T, Takeda K, et al. Yokukansan, a traditional Japanese herbal medicine, alleviates the emotional abnormality induced by maladaptation to stress in mice. Phytomedicine 2014;21(3):363-371. doi:10.1016/j.phymed.2013. 08.025 .

[22] Rodríguez Echandía EL, Broitman ST, Fóscolo MR. Effect of the chronic ingestion of chlorimipramine and desipramine on the hole board response to acute stresses in male rats. Pharmacol Biochem Behav 1987;26(2):207-210. doi:10.1016/0091-3057(87)90106-7.

[23] Takeda H, Tsuji M, Matsumiya T. Changes in head-dipping behavior in the hole-board test reflect the anxiogenic and/or anxiolytic state in mice. Eur J Pharmacol 1998;350(1):21-29. doi:10.1016/S00142999(98)00223-4.

[24] Saitoh A, Hirose N, Yamada M, Yamada M, Nozaki C, Oka T, et al. Changes in emotional behavior of mice in the hole-board test after olfactory bulbectomy. J Pharmacol Sci 2006;102(4):377-386. doi:10.1254/jphs.FP0060837.

[25] Yamauchi R, Wada E, Yamada D, Yoshikawa M, Wada K. Effect of beta-lactotensin on acute stress and fear memory. Peptides 2006;27(12):3176-3182. doi:10.1016/j.peptides.2006.08.009.

[26] Kamei J, Hirose N, Oka T, Miyata S, Saitoh A, Yamada M. Effects of methylphenidate on the hyperemotional behavior in olfactory bulbectomized mice by using the hole-board test. J Pharmacol Sci 2007;103(2):175-180. doi:10.1254/jphs.FP0061021.

[27] Heidmann DE, Metcalf MA, Kohen R, Hamblin MW. Four 5-hydroxytryptamine $e_{7}\left(5-\mathrm{HT}_{7}\right)$ receptor isoforms in human and rat produced by alternative splicing: species differences due to altered intron-exon organization. J Neurochem 1997;68(4):1372-1381. doi:10.1046/ j.1471-4159.1997.68041372.x. 
[28] Jasper JR, Kosaka A, To ZP, Chang DJ, Eglen RM. Cloning, expression and pharmacology of a truncated splice variant of the human 5- $\mathrm{HT}_{7}$ receptor (h5- $\mathrm{HT}_{7 \mathrm{~b}}$ ). $\mathrm{Br} J$ Pharmacol 1997;122(1):126-132. doi:10.1038/sj.bjp.0701336.

[29] Krobert KA, Bach T, Syversveen T, Kvingedal AM, Levy FO. The cloned human $5-\mathrm{HT}_{7}$ receptor splice variants: a comparative characterization of their pharmacology, function and distribution. Naunyn Schmiedebergs Arch Pharmacol 2001;363(3):620-632. doi:10.1007/ s002100000369.

[30] Mahé C, Bernhard M, Bobirnac I, Keser C, Loetscher E, Feuerbach D, et al. Functional expression of the serotonin $5-\mathrm{HT}_{7}$ receptor in human glioblastoma cell lines. Br J Pharmacol 2004;143(3):404-410. doi:10.1038/sj.bjp.0705936.

[31] Mahé C, Loetscher E, Dev KK, Bobirnac I, Otten U, Schoeffter P. Serotonin $5-\mathrm{HT}_{7}$ receptors coupled to induction of interleukin-6 in human microglial MC-3 cells. Neuropharmacology 2005;49(1):40-47. doi:10.1016/j.neuropharm.2005.01.025.

[32] Boess FG, Martin IL. Molecular biology of 5-HT receptors. Neuropharmacology 1994;33(3-4):275-317.

[33] Grewal SS, York RD, Stork PJ. Extracellular-signal-regulated kinase signaling in neurons. Curr Opin Neurobiol 1999;9(5):544-553. doi:10.1016/S0959-4388(99)00010-0.

[34] Galeotti N, Ghelardini C. Regionally selective activation and differential regulation of ERK, JNK and p38 MAP kinase signalling pathway by protein kinase $C$ in mood modulation. Int J Neuropsychopharmacol 2012;15(6):781-793. doi:10.1017/S1461145711000897.

[35] Errico M, Crozier RA, Plummer MR, Cowen DS. 5-HT 7 receptors activate the mitogen activated protein kinase extracellular signal related kinase in cultured rat hippocampal neurons. Neuroscience 2001;102(2):361-367. doi:10.1016/S0306-4522(00)00460-7.

[36] Lin SL, Johnson-Farley NN, Lubinsky DR, Cowen DS. Coupling of neuronal $5-\mathrm{HT}_{7}$ receptors to activation of extracellular-regulated kinase through a protein kinase A-independent pathway that can utilize Epac. J Neurochem 2003;87(5):1076-1085. doi:10.1046/j.14714159.2003.02076.x.

[37] Norum JH, Méthi T, Mattingly RR, Levy FO. Endogenous expression and protein kinase A-dependent phosphorylation of the guanine nucleotide exchange factor Ras-GRF1 in human embryonic kidney 293 cells. FEBS J 2005;272(9):2304-2316. doi:10.1111/j.17424658.2005.04658.x.

[38] Leopoldo M, Lacivita E, Contino M, Colabufo NA, Berardi F, Perrone R. Structure-activity relationship study on $N$-(1,2,3,4-tetrahydronaph- thalen-1-yl)-4- aryl-1-piperazinehexanamides, a class of 5- $\mathrm{HT}_{7}$ receptor agents. 2. J Med Chem 2007;50(17):4214-4221. doi:10.1021/ jm070487n.

[39] Costa L, Spatuzza M, D’Antoni S, Bonaccorso CM, Trovato C, Musumeci SA, et al. Activation of $5-\mathrm{HT}_{7}$ serotonin receptors reverses metabotropic glutamate receptor-mediated synaptic plasticity in wild-type and Fmr1 knockout mice, a model of Fragile X syndrome. Biol Psychiatry 2012;72(11):924-933. doi:10.1016/j.biopsych.2012.06.008.

[40] Costa L, Sardone LM, Lacivita E, Leopoldo M, Ciranna L. Novel agonists for serotonin $5-\mathrm{HT}_{7}$ receptors reverse metabotropic glutamate receptor-mediated long-term depression in the hippocampus of wild-type and Fmr1 KO mice, a model of Fragile X Syndrome. Front Behav Neurosci 2015;9:65. doi:10.3389/fnbeh.2015.00065.

[41] De Filippis B, Chiodi V, Adriani W, Lacivita E, Mallozzi C, Leopoldo M et al. Long-lasting beneficial effects of central serotonin receptor 7 stimulation in female mice modeling Rett syndrome. Front Behav Neurosci 2015;9:86. doi:10.3389/fnbeh.2015.00086.

[42] Tokarski K, Zahorodna A, Bobula B, Grzegorzewska M, Pitra P, Hess G. Repeated administration of citalopram and imipramine alters the responsiveness of rat hippocampal circuitry to the activation of 5- $\mathrm{HT}_{7}$ receptors. Eur J Pharmacol 2005;524(1-3):60-66. doi:10.1016/j. ejphar.2005.09.014.

[43] Pitra P, Tokarski K, Grzegorzewska M, Hess G. Effects of repetitive administration of tianeptine, zinc hydroaspartate and electroconvulsive shock on the reactivity of $5-\mathrm{HT}_{7}$ receptors in rat hippocampus. Pharmacol Rep 2007;59(6):627-635.

[44] Samarajeewa A, Goldemann L, Vasefi MS, Ahmed N, Gondora N, Khanderia C, et al. 5-HT7 receptor activation promotes an increase in TrkB receptor expression and phosphorylation. Front Behav Neurosci 2014;8:391. doi:10.3389/fnbeh.2014.00391.

[45] Speranza L, Giuliano T, Volpicelli F, De Stefano ME, Lombardi L, Chambery A, et al. Activation of 5-HT7 receptor stimulates neurite elongation through mTOR, Cdc42 and actin filaments dynamics. Front Behav Neurosci 2015;9:62. doi:10.3389/fnbeh.2015.00062.

[46] Andreetta F, Carboni L, Grafton G, Jeggo R, Whyment AD, van den Top $\mathrm{M}$, et al. Hippocampal 5- $\mathrm{HT}_{7}$ receptors signal phosphorylation of the GluA1 subunit to facilitate AMPA receptor mediated-neurotransmission in vitro and in vivo. Br J Pharmacol 2016;173(9):1438-1451. doi:10.1111/bph.13432.

[47] Duman RS, Aghajanian GK, Sanacora G, Krystal JH. Synaptic plasticity and depression: new insights from stress and rapid-acting antidepressants. Nat Med 2016;22(3):238-249. doi:10.1038/nm.4050. 